\title{
Adrenocorticotropic Hormone, Glucose and Displacement Activities in Pigeons
}

\author{
By Juan D. Delius, Barbara Craig and Catherine Chaudoir
}

With 6 figures

\begin{abstract}
The possibility that displacement activities might be consequences of stress-induced humoral responses was investigated. Adrenocorticotropic hormone and glucose were injected into the brain ventricles of unrestrained domestic pigeons. ACTH leads to an increased frequency of yawning and headshaking and glucose to a decrease in arousal. It is concluded that these behavioural responses correspond partly with the displacement activities shown by birds. The role of the cerebrospinal fluid as a mediatcr of behaviourally active substances is discussed.
\end{abstract}

\section{Introduction}

In many situations that appear to involve a measure of psychological stress animals often show behavioural responses that strike the observer as being both functionally and motivationally inappropriate. These responses, as for example the occurrence of grooming or feeding movements in the middle of aggressive or courtship encounters, have been collectively labeled displacement activities and their causal background has been the subject of much research and speculation (HINDE 1970). The present study was motivated by the general working hypothesis that the occurrence of at least some of the displacement activities may be the direct result of humoral changes that are well known to follow the induction of stress (DeLius 1970 a; see also ANDREW 1956, Morris 1956).

Among these responses are the secretion of adrenocorticotropic hormone (ACTH) and the mobilization of glucose. Since neurons sensitive of titre variations of these substances have been described (e. g. Pfaff et al. 1971, OOMuRA et al. 1969), the stress-induced alterations could potentially control the behaviour that accompanies or follows stress. This paper describes experiments exploring this possibility. We have begun by studying the behavioural effects of intraventricular administration of ACTH and glucose upon the behaviour of freely moving pigeons.

The research was supported by a grant from the Science Research Council (London) to J. D. D. The assistance of Mr. D. Harper, Miss Marie Cawton and Mrs. Joan Emery is gratefully acknowledged. 


\section{Methods}

Adult domestic pigeons (Columba livia) of unknown sex were used in all experiments. They were kept on ad lib food and water throughout. Under Equithesin $(0.25 \mathrm{~m} / 100 \mathrm{~g}$ bodyweight, intramuscular) anaesthesia and while its head was held in a headholder (KARTEN and Hodos 1967) each bird was equipped with a ventricular cannula. The cannulas were made of stainless steel tubing (outer diameter $0.7 \mathrm{~mm}$ ) and had a stainless steel pin plug retained in place by an elastic polyethylene collar (Fig. 1). Guided by skull landmarks they were driven by percussion through the bone and the brain into one of the lateral ventricles of the telencephalon. The location of the cannula tip was ascertained by intermittent removal of the plug pin: when the ventricle lumen was reached the cerebrospinal fluid (CSF), which is at a positive pressure, oozed out. The cannula was then anchored with dental cement to the skull, which had previously been pitted with a dental drill.

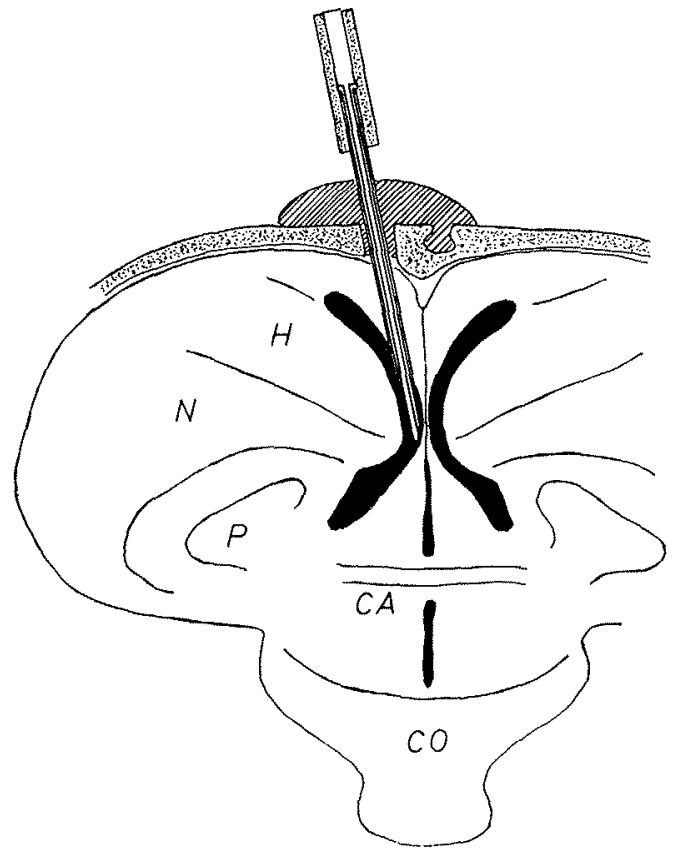

Fig. 1: Schematic diagram showing the intraventricular cannula and its position in the lateral ventricle of the forebrain of a pigeon. CA anterior commissure, $\mathrm{CO}$ chaisma opticum, H hyperstriatum, $\mathrm{N}$ neostriatum, $\mathrm{P}$ paleostriatum

Experiments began at least 4 days after surgery and were carried out in a cage provided with a one-way mirror observation port (Fig. 2). Each subject had opportunity to acclimatize to this test cage and the noise environment for at least 3 days. For the actual administration of drug solution the pin plug was removed and a length of polyethylene tubing (outer diameter $1.4 \mathrm{~mm}$ ), preloaded with solution was slipped over the cannula inlet. The tubing was suspended from a counterweighted lever allowing virtually unrestricted movements by the pigeon. A period of at least $15 \mathrm{~min}$ was allowed for the pigeon's re. covery from the handling. Behaviour observations began $10 \mathrm{~min}$ befor the injection and continued for at least $50 \mathrm{~min}$ after the injection. A standard $0.1 \mathrm{ml}$ of drug solution was injected over $45 \mathrm{sec}$ with the aid of a micrometer syringe. The volume injected replaced approximately the quantity of CSF lost when the pin plug was removed.

In preliminary trials 25 behaviour patterns that occurred with some frequency under the experimental conditions, were identified and labeled with suitable abbreviations. Among these were feeding, drinking, preening, single wing stretching, stretching both wings, wing flapping, yawning, shaking, headshaking and eye closing. Additionally a scale of six states of arousal was defined on the basis of observable behavioural criteria such as degree of plumage ruffling, neck stretching, degree of eye closure, head and body movements and locomotion (Tab. 1). The states ranged from asleep through drowsy, relaxed, alert, active to excited. The same arousal scale was previously used by one of us (J. D. D.) in an unpublished study where arousal scores were correlated with electroencephalographic recordings graded for arousal. Reasonable agreement between them $(r \approx 0.60)$ was obtained.

Observations were timed with the aid of a pulse generator that gave a faint bleep every $30 \mathrm{sec}$. For each time interval, all behaviour patterns that occurred within it as well as the current state of arousal were noted. The subjects underwent not more than one trial per day. Systematic experimental designs were attempted throughout. The cannulas of some subjects, however, became blocked up before the completion of the intended series of trials. This meant that to achieve a full design a surplus number of subjects had to be operated upon and tested. 


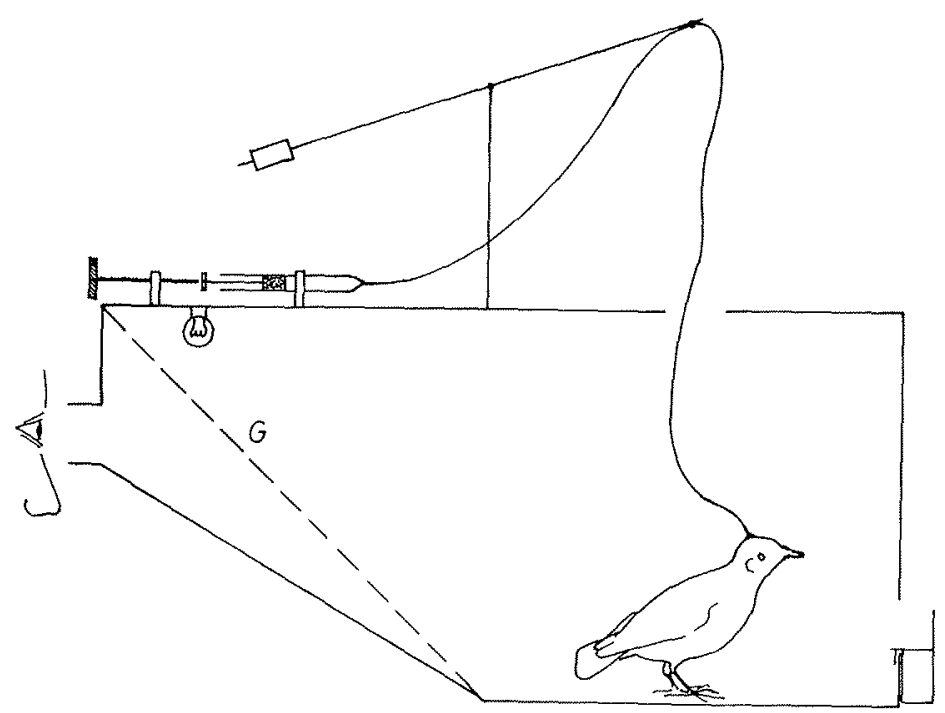

Fig. 2: Schematic diagram of the testing cage. G: glass plate

Table 1:

\begin{tabular}{|c|c|c|c|c|c|c|c|}
\hline Rating & State & Plumage & Neck & $\begin{array}{l}\text { Head } \\
\text { movements }\end{array}$ & $\begin{array}{l}\text { Body } \\
\text { posture }\end{array}$ & Locomotion & Eyes \\
\hline 1 & Asleep & fluffed & short & none & squat & none & closed \\
\hline 2 & Drowsy & fluffed & short & some & squat & none & blinking \\
\hline 3 & Relaxed & fluffed & normal & some & normal & none & blinking \\
\hline 4 & Alert & sleek & normal & some & normal & some & open \\
\hline 5 & Active & sleek & extended & many & erect & some & open \\
\hline 6 & Excited & sleek & extended & many & normal & much & wideopen \\
\hline
\end{tabular}

The saline used as medium for the ACTH and glucose was based on WHITE's formula tion, intended to match avian blood plasma (LOCKwood 1961). Since, however, avian cerebrospinal fluid, otherwise of a composition very similar to plasma, has half the concentration of glucose (ANDERSON and HAZELWOOD 1969) a corresponding adjustment was made for the ACTH experiments. For the glucose experiments, of course, its concentration was varied, as will be detailed later. To avoid degradation, in every case the glucose was added to the saline immediately before each trial. ACTH and albumen (both porcine) were obtained from Sigma, all other drugs from British Drug Houses.

In a preliminary experiment it was ascertained that the intraventricular administration of $0.1 \mathrm{ml}$ of the saline caused no detectable behavioural effects, when compared with dummy administration trials ( 4 trials of each type, 2 subjects).

At the end of the experiment the animals were sacrificed and perfused with formalin. Freeze sections of their brains stained with cresyl-violet, showed that the cannula tips were all located within either of the lateral ventricles at approximately the stereotactic coordinates (KARTEN and Hodos 1967) A 8, D 10, L 1.

We shall also refer to, but not describe, results of a series of trials which was carried out under conditions similar to those described above, but where we attempted to assess the effect of stress on the behaviour of normal pigeons by observing them after a brief "scaring" incident (sudden, unexpected attempt to catch them). We will also mention observations on pigeons that were temporarily thwarted from gaining access to their habitual food source or that had just been transferred to a novel, unusual cage. From several subjects in these trials we also recorded and assessed the electroencephalogram from one or more forebrain structures (see above). 


\section{Results}

ACTH administration. A total of 36 trials were performed on 4 pigeons using control saline and 3 solutions of hormone in saline; in each trial either $0,1,2$ or 4 international units (IU) of ACTH were administered.

Examination of behavioural data showed that only two of the behaviour categories recorded were significantly affected by the hormone administration: yawning and head shaking. Fig. 3 shows that 2 IU of ACTH caused a delayed increase in the occurrence of these two behaviour patterns, which then persisted until the end of the observation period $50 \mathrm{~min}$ after the injection. Two extended trials with the same dose revealed that the behaviours only returned to normal levels some two hours after injection. For yawning the effect set in with a latency of less than 5 min and reached its maximum some 15 min after the injection, whereas headshaking began after a latency of approximately 5 min and only reached its maximum some $35 \mathrm{~min}$ after the injection.

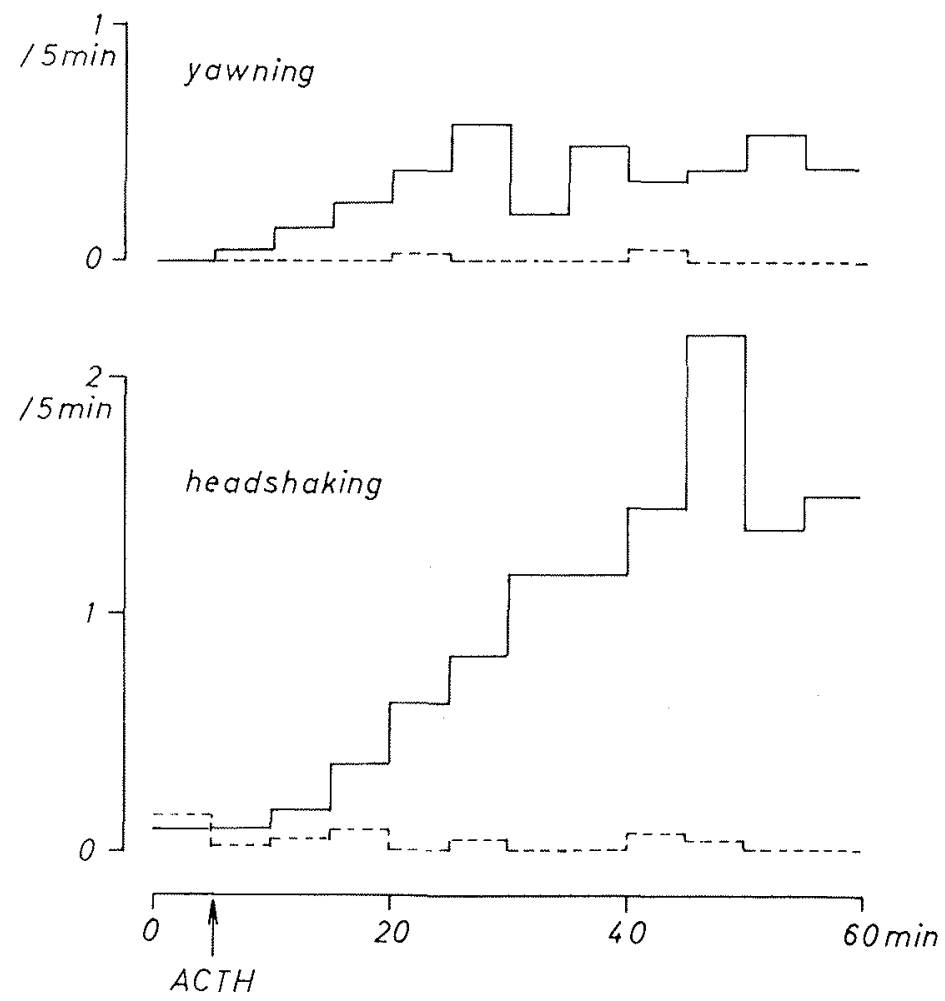

Fig. 3: Effect of the administration of 2 IU ACTH into the lateral ventricle of pigeons $(\mathrm{N}=3 \times 6$ trials $)$ on the frequency of yawning and headshaking. The dotted line represents the result of control saline injections

A systematic experimental design was completed with 2 IU ACTH and control saline treatments on 3 subjects with a total of 18 trials. Separate analysis of variance on the number of headshakes and yawns occurring during the 50 min following each injection showed that the effect was significant for both patterns (control: 0.3 headshakes, 0 yawns; 2 IU ACTH: 13.5 head- 
Fig. 4: Dose dependency of ACTH clicited yawning and headshaking frequency increments

shakes, 4.0 yawns; F-test, $\mathrm{p}<0.01$ ). The magnitude of the effect varied somewhat in the different pigeons though not significantly. This might be related to small variations in cannula positions. Fig. 4 based on all trials and subjects but not following a systematic design, indicates a dose dependency such that a maximal response occurred

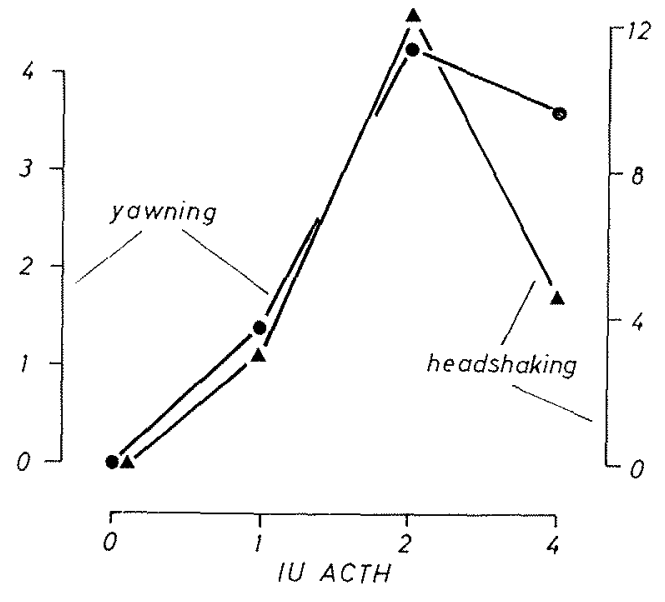
with 2 IU doses of ACTH and decreased effects both with lower and higher dosages.

The possibility that the effect of $\mathrm{ACTH}$ might be a quite unspecific response to proteinic substances was checked on one subject, where, in three 50 min trials, injecting albumen in an equivalent amount by weight to 4 IU ACTH did not yield any yawning or headshaking, whereas that dosage of hormone in the same individual had yielded a mean 3.3 yawns and 4.9 headshakes per trial.

While the frequency of both behaviours increased with the ACTH administration other patterns normally associated with them were at most only transitorily affected. A temporary passivity and a transitory increase in preening was noticeable in the ACTH treated animals but was not reflected significantly in our analysis of the arousal measures. Normally, yawning and headshaking are both temporally linked with preening. Both patterns showed a decreased linkage with preening and stretching behaviour during ACTH administration trials as compared with control trials. Table 2 shows this difference in contingency by listing the instances in which either or both of the two behaviours was shown within a period of 1 min preceding or following a preening or stretching movement. The nonhomogeneity of the distribution as judged by a $\chi^{2}$ test is significant at the $p<0.001$ level.

Table 2:

\begin{tabular}{|c|c|c|}
\hline Context & ACTH & Control \\
\hline Grooming & $11 \%$ & $46 \%$ \\
\hline Non-grooming & $89 \%$ & $54 \%$ \\
\hline$N$ & 166 & 30 \\
\hline
\end{tabular}

Glucose administration. In preliminary experiments relating to the previous experiment it was noticed that the variations of the glucose content of the saline used had a marked influence on the behaviour of the subjects. This was investigated further in a total of 35 trials on 6 subjects involving the injection of $0.1 \mathrm{ml}$ saline containing either $0,0.5,1.25$ or $2 \mathrm{mg}$ glucose.

The most striking behavioural effect induced by the glucose injection was the decrease of activity and increase of sleepiness as measured by the arousal index mentioned earlier. Fig. 5 illustrates this for the $1.25 \mathrm{mg}$ glucose dose. 


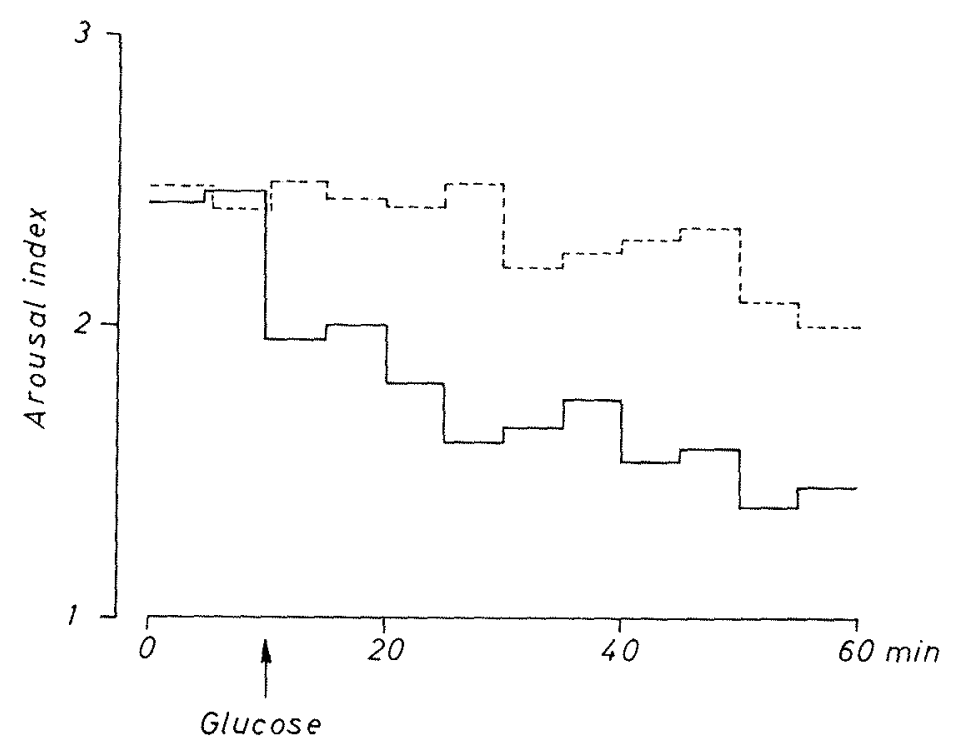

Fig. 5: Effect of the administration of $1.25 \mathrm{mg}$ of glucose into the lateral ventricle of pigeons $(N=4 \times 4$ trials $)$ on their arousal level. The dotted line represents the result of control saline in jections

The effect was virtually immediate with a latency of 1 min or less with the administration of 1.25 and $2 \mathrm{mg}$ glucose. The activity decreases persisted for about $90 \mathrm{~min}$ in the case of the $1.25 \mathrm{mg}$ dose and for over $120 \mathrm{~min}$ in the case of the $2 \mathrm{mg}$ dose, as was ascertained in 4 trials with extended observation periods. An analysis of variance based on a completed experimental design on 4 birds showed that glucose levels significantly affect the level of activities of the subjects (F test, $\mathrm{p}<0.01$ ). Fig. 6 shows that the effect is dose-dependent and a Sheffé test based on the preceding analysis of variance shows that the main difference arises between the 0.5 and $1.25 \mathrm{mg}$ glucose treatments $(\mathrm{p}<0.01)$.

A series of 5 control trials without any injection but otherwise following the same procedure was carried out on 2 of the pigeons used in the experimental design just mentioned. This series showed that their arousal response did not differ significantly (F test, $\mathrm{p}>0.05$ ) from the response to 0 and $0.5 \mathrm{mg}$ glucose administration. The gradual, slight decay in arousal that is noticeable for these two later treatments was also apparent in the controls. They are probably explained by circadian activity trends: experiments were either conducted

Fig. 6: Dose dependency of glucose elicited arousal decrements and eye closure increments
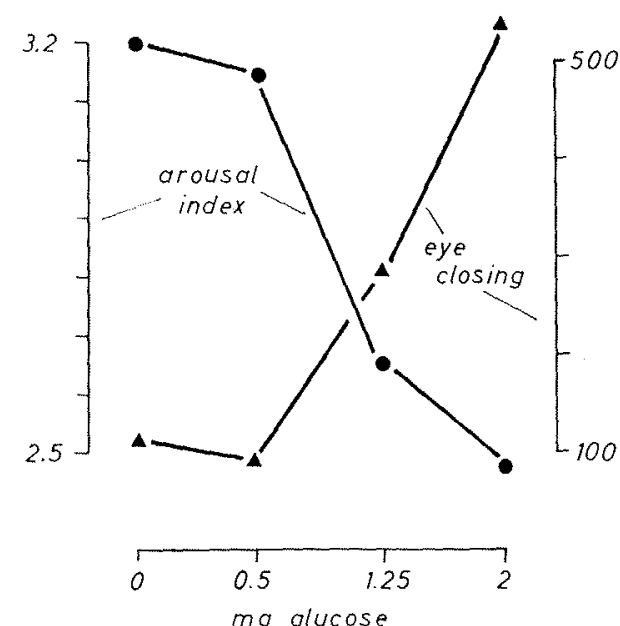
in the late morning or late afternoon, that is just before the two circadian activity minima that are typical for pigeons. In a series of 6 trials on one subject we also compared the effect of administering $1.25 \mathrm{mg}$ of glucose with that of injecting the same amount of xylose, a metabolically inert sugar. While xylose might have produced a slight dearousal effect it was markedly less than that elicited by glucose ( $F$ test, $p<0.05$ ). These results showed that the response to glucose that we have just described is to some extent at least specific.

The measure of arousal that was used is a complex index reflecting the occurrence of several behaviour patterns, some of them continuously variable such as neck elongation or locomotion. One component however was of a more discrete nature: eye closing. It was recorded separately as representing a more "objective" measure of wakefulness than the index that certainly involved a degree of "subjective" judgement. Fig. 6 presents its dose dependency: it mirrors reasonably closely the dose-response curve of the arousal index.

Apart from the change in arousal described above there is a suggestion in the data that the lower doses of glucose $(0.5 \mathrm{mg}, 1.25 \mathrm{mg})$ caused a transient increase in the occurrence of stretching (double wing stretching and single wing stretching) and preening as compared both with the saline and the highest dose of glucose $(2 \mathrm{mg})$. However, there is not sufficient data to prove this statistically.

\section{Discussion}

In a series of studies Ferrari and collaborators (summary in GesSa et al. 1967) have described the behavioural responses elicited by injection of small quantities of ACTH, and related substances, into the ventricles in a number of mammalian species. In all of them ACTH, at dosages of 0.12 IU per $\mathrm{kg}$ body weight, induced fits of yawning and stretching behaviour (see RASA 1971 for similar findings in fish!). This partially contrasts with our results where the responses induced were yawning and head shaking, although pigeons possess in their repertoire stretching movements that seem analogous to those of mammals (and conversely mammals show a head shaking response equivalent to that of birds). A further difference is the considerably shorter latency with which the behavioural effects occur in pigeons $(\approx 5 \mathrm{~min}$ versus $\approx 30 \mathrm{~min})$. Since we found the latency to be virtually independent of the hormone dosage it seems likely that this shortness is due to faster transport from the injection site to the receptor sites, perhaps connected with the smallness of the pigeon ventricles.

How do these responses relate to normally occurring behaviour, in particular, to displacement activities? Stretching and yawning are associated in mammals with somnolence (even though the patterns themselves are accompanied by transitory electroencephalographic arousal [GESSA et al. 1967]); that is they occur before and after sleep or during periods of drowsiness. However, they are also shown in situations of marked wakefulness and stress: cats often stretch and yawn when mildly threatened (own observations), dogs sometimes perform this behaviour in tense social encounters (SCHMIDT 1956) and so do primates (ANDREw 1963). Similarly yawning (again normally emitted in the context of drowsiness) and headshaking is elicited by stressing situations in birds. Thus headshaking is an anxiety response in terns, Sterna sp. (vaN IERSEL and Bol 1958) and yawning appears in similar contexts in gulls Larus sp. (Delius 1967). Both responses are also shown more often than 
normally by pigeons when placed in novel, strange environments, though headshaking not strikingly so.

Hence it seems possible that the wellknown secretion of ACTH that is induced by stress might facilitate these displacement responses. But there are some difficulties with this hypothesis. ACTH is secreted by the adenohypophysis directly into the bloodstream and thus would only reach the CSF after filtration through the dhorid plexin (there is evidence that the blood-liquor [ANDERSON and HAZELWOOD 1969]), or alternatively reach receptor sites directly through the cerebral circulation. However, some preliminary trials, in which we injected up to $8 \mathrm{IU}$ of ACTH into a pigeon with a chronic jugular vein cannula, failed to produce any behavioural effects even though the treatments should have lead to ACTH circulating levels well in excess of the normal one (in

There is an alternative though. In his experiment Ferrari et al. (1963) showed that polypeptide fractions containing the aminoacids 4 to 10 of the effective in releasing the yawning-stretching response. This aminoacid sequence is also present in MSH (melanocyte stimulating hormone) and LPH (lipotrophic hormone) and indeed intraventricular administration of the first of these has been shown to be capable of releasing the behavioural syndrome appears to reflect a shared synthesis pathway (SCOTT et al. 1973) existence of further derivatives with the same sequence seems possible. Birds possess a significant extrahypophyseal hypothalamic source of a substance, similar in its peripheral action to ACTH, that presumably incorporates the above sequence (SALEM et al. 1970, PECZELY 1972). It is thus conceivable that this corticotropic substance reaches the ventricle directly, much as the neurohypophysis hormones and releasing factors are known to do (KNIGGE and JosePH 1974). Ar any rate, a profusion of netronal and to do (KNy structures cavity have been described (STERBA 1969). Nothing can be said of course as to whether the corticotrophic substance occurs with the high titres that our experiments suggest are necessary for the release of the behavioural effect. Obviously this alternative requires a good deal of further supporting evidence to lift it

from the realm of speculation.
The presence of a specific sleep-promoting polypeptide in the CSF of mammals (FENCL et al. 1971) finally raises the possibility that the yawning somnogenic polypeptide incorporating the critical 4-10 aminoacid sequence mentioned above.

It must also be mentioned that intraventricular administration of submicrogram quantities of zinc has been shown to elicit yawning and stretching in rats (IzUMr et al. 1973) much as ACTH does. Significantly, however, serum zinc levels in rats have quite independently been found to correlate closely with ACTH levels (FLYNN et al. 1971) indicating some special relationship

We now turn to the role of glucose. It is, of course, well known that in mammals plasma glucose levels rise following the induction of stress; a similar changes in plasma glucose are reflected in concomitant CSF glucose level changes and this correspondence also operates in birds (ANDERSON and HAZEL- 
WOOD 1969). Compared with mammals, incidentally, birds manifest higher baseline levels of both plasma and CSF glucose. In pigeons these levels are respectively $3.3 \mathrm{mg} / \mathrm{ml}$ and $1.4 \mathrm{mg} / \mathrm{ml}$ (own determinations, colorimetric orthotoluidine method [Sigma 1971], few samples; see also ANDERson and HAZELW OOD 1969 for chicken levels), compared for example with man, where the corresponding values are $0.9 \mathrm{mg} / \mathrm{ml}$ and $0.6 \mathrm{mg} / \mathrm{ml}$. It may be, though, that in birds CSF glucose levels are more independent of plasma glucose levels than in mammals. A special glycogen store, the glycogen body located in the sacral region of the spinal cord totally surrounds the central canal ependyma and is separated from the CSF containing subarachnoid space over a large area by only the pia mater while being only poorly vascularized. It does not release glucose in response to the same agents that cause a rise in blood glucose levels, but it may be under direct neural cholinergic control (Paul 1973). Under what behavioural circumstances it is activated however is unknown.

We estimate that our injection of $1.25 \mathrm{mg}$ glucose solution into the cerebral ventricular cavity of a pigeon would lead to a $90 \%$ increase of the CSF glucose level. That presupposes an immediate, even diffusion of the glucose dose through the estimated $1 \mathrm{ml}$ of CSF contained in the cerebral ventricles. Assuming that the cannula tips were not located in the immediate neighbourhood of the relevant glucose receptors and that the diffusion process is gradual and accompanied by the removal of excess glucose from the relevant fluid compartment, the effective glucose level could be lower and well within the bounds of physiological glucose level changes.

Drowsiness, with all the electroencephalographic signs of diminished wakefulness, is a common response of pigeons to behavioural stress situations such as an exposure to a novel environment or to a frustrating or anxiety producing procedure. It is often accompanied or followed by comfort movements, such as yawning, stretching, preening and also pecking, before the animal returns to a normal, alert, active behavioural state. Similar response patterns have also been described for other birds species (Delius 1967, $1970 \mathrm{~b}$; Gurron and Woopgush 1967). The behavioural syndrome brought about by the increased levels of CSF glucose partially reproduces this. It is thus possible that stress induced elevations of liquor glucose levels could be causally implicated in producing the behaviour syndrome just mentioned.

We note also that HaLl (1971) observed a drowsiness response in domestic chicks when he loaded their crops with glucose (for example with $1.5 \mathrm{ml}$, $0.75 \mathrm{~mol}$ solution) and additionally noticed an increase in nonfeeding pecking (actual feeding as in our pigeons, was depressed [but see SMITH and BRIGHTTAYLOR]), a response that in the adult chicken has been described as displacement activity (FEEKEs 1972). Similar responses were noticed following the intracerebral introduction of minute quantities of crystalline glucose, particularly when the loci so stimulated were in the hypothalamus. Metabolically inert sugars did not have this effect, as our own experiments showed too. In mammals reduced activity and drowsiness have been casually mentioned as concomitants of elevated plasma glucose titres in connection with investigations into the role of glucose in hunger regulation. The well known postprandial drowsiness and indeed the postprandial grooming that is seen in some mammals (BAILliE and Morrison 1963) might be caused by the plasma glucose rise that accompanies feeding (STEFFENS 1969). Certain hypothalamic neurons in mammals have been found to respond to glucose concentration changes and such units could obviously mediate these behavioural effects (BROWN and Melzack 1969, Oomura et al. 1969). 
Our experiments thus suggest that known humoral consequences of stress could be involved, perhaps cooperatively, in the causation of displacement activities. Clearly, considerably more work is needed before this can be claimed with certainty, particularly in view of the profusion and complexity of the physiological stress responses that cond be potentilly in colved. We spinal fluid could play an important role as a carrier of behaviourally active substances, liquormones as we have tentatively called them.

\section{Summary}

Pigeons with cannulas chronically implanted in the lateral forebrain entricles were injected with small quantities of adrenocorticotropic hormone (Anits) elicited bouts of yawning and headshaking; glucose administration (for example $1.25 \mathrm{mg}$ ) elicited drowsiness. Both effects had a short latency $\approx 5 \mathrm{~min}$ ). These results are discussed in relation to the displacement behaviour shown by pigeons and other birds in stressful conflict situations. It is argued that some of this behaviour may be mediated by central nervous action of stress induced humoral responses such as the increased levels of ACTH and glucose. The role of the ventricular liquor as a possible

\section{Zusammenfassung}

Tauben, denen Kanülen in die lateralen Vorderhirnventrikel chronisch eingepflanzt worden waren, bekamen kleinere Mengen von adrenocorticotropem Hormon (ACTH) und Glukose injiziert. ACTH (z. B. 2 internationale Einheiten) löste eine Serie von Gähn- und Kopfschürttelbewegungen aus, während Glukose-Injelktionen (z. B. 1,25 mg) eine Verminderung des Wach-
heitszustandes (arousal) herbeiführten. Beide Reaktionen hatten eine kurze heitszustandes (arousal) herbeiführten. Beide Reaktionen hatten eine kurze
Latenz $(\approx 5 \mathrm{~min})$. Diese Ergebnisse werden im Zusammenhang mit dem Übersprungverhalten, das Tauben und andere Vögel in streßvollen Konfliktsituationen zeigen, besprochen. Es wird argumentiert, daß dieses Verhalten zum Teil auf zentral-nervöse Wirkungen der durch Streß induzierten hormonalen Reaktionen, wie z. B. die erhöhten ACTH- und Glukosepegel, zurïckgehen könnte. Die mögliche Rolle des ventrikulären Liquors als Trägermedi
diese beiden Substanzen wird anhand bestehenden Wissens besprochen.

\section{Literature cited}

ANDERSON, D. K., and R. L. HAZELWOOD (1969): Chicken cerebrospinal fluid: normal composition and response to insulin administration. J. Physiol. (Lond.) 202, 83-95. ANDREV, Emberiza spp. Brit. J. anim. Behav. 4, 41-45. ANDREW, R. J. (1963): The origin and evolution of the calls and facial expression of the primates. Behaviour 20, 1-109 - BAillie,

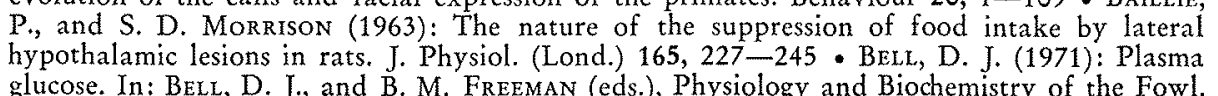

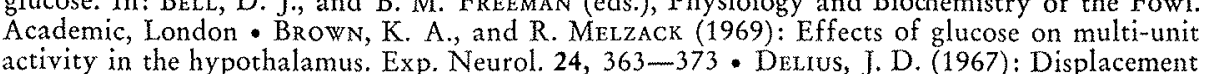


activities and arousal. Nature 214, 1259-1260 - Delius, J. D. (1970a): Irrelevant behaviour, information processing and arousal homeostasis. Psychol. Forsch. 33, 165-188 - Delius, J. D. (1970b): The effects of daytime, tides and other factors on some activities of lesser black-backed gulls, Larus fuscus. Rev. Comp. Animal 4, 3-11 - Delius, J. D. (1973): Agonistic behaviour of juvenile gulls, a neuroethological study. Anim. Behav. 21, 236-246 - FeEkes, F. (1972): Irrelevant ground pecking in agonistic situations in Burmese red jungle fowl. Behaviour 43, 186-326. Fencl, V., G. Koski and J. A. Pappenhermer (1971): Factors in cerebrospinal fluid from goats that affect sleep and activity in rats. J. Physiol. (Lond.) 216, 565-589 - Ferrari, W., G. L. Grssa and L. Vargru (1963): Behavioural effects induced by intracisternally injected ACTH and MSH. Ann. N. Y. Acad. Sci. 104, 330-345 - FL.YNN, A., W. J. Pories, W. H. Strain and O. A. Hill (1971): Mineral element correlation with adenohypophyseal-adrenal cortex function and stress. Science 173, 1035-1036 - Gessa, G. L., M. Pisano, L. Vargiu, F. Crabai and W. Ferrari (1967): Stretching and yawning movements after intracerebral injection of ACTH. Rev. Can. Biol. 26, 229-236 - Gray, C. H., and A. L. Bacharach (eds.) (1967): Hormones in Blood. Academic, London - Gurton, P., and D. G. M. Woodgust (1967): Studies on thwarting in the domestic fowl. Rev. comp. anim. 5, 1-23 - Hall, T. J. (1971): Effects on feeding, aggression and copulation of sugars given intracranially or enterally. Ph. D. thesis, University of Sussex, Brighton - Hinde, R. A. (1970): Animal Behaviour. McGraw Hill, London - IERsel, J. J. A. van, and A. C. A. Bor. (1958): Preening of two tern species, a study on displacement activities. Behaviour 13, 1-88 - Izumi, K., J. Donaldson and A. Barbeau (1973): Yawning and stretching in rats induced by intraventricularly administered zinc. Life Science 12, 203-210 - KARTEN, H. J., and W. Hodos (1967): A stcreotaxic Atlas of the Brain of the Pigeon. Johns Hopkins, Baltimore - KNIGGE, K. M., and S. A. Joseph (1974): Thyrotropin releasing factor (TRF) in cerebrospinal fluid of the 3rd ventricle of rat. Acta Endocrinol. 76, 209-213 - LAHIRI, P., I. GosH and A. Gosm (1967): Investigations on the functional relationship between adrenomedullary catechol hormones and blood sugar level in the pigeon. Folia Biol. 15, 35-41. Lockwood, A. P. M. (1961): Ringer solutions and some notes on the physiological basis of their ionic composition. Com. Biochem. Physiol. 2, 241-289 - Morris, D. (1956): The feather postures of birds and the problem of the origins of social signals. Behaviour 9, 75-114 - Oomura, Y., T. ONO, H. Oozuyama and M. J. WAGNER (1969): Glucose and osmosensitive neurons of the rat hypothalamus. Nature 222, 282-284 - Paur, E. (1973): Histologische und quantitative Studien am lumbalen Glykogenkörper der Vögel. Z. Zellforsch. 145, 89-101 - PECZELY, P. (1972): Corticotropic and ADH System in the hypothalamus of the pigeon. Acta Physiol. Acad. Sci. Hung. 41, 37-47 - Pfaff, D. W., A. T. A. Silva and J. M. Werss (1971): Telemetered recordings of hormone effects on hippocampal neurons. Science 172, 394-395 . RAsA, O. A. E. (1971): The causal factors and function of yawning in Microspathodon chrysurus. Behaviour 39, 39-57 - SALEM, M. H. M., H. W. NoRton and A. V. Nalbandov (1970): A study of ACTH and CRF in chickens. Gen. comp. Endocr. 14, 270-280. SCHMIDT, H. D. (1956): Das Verhalten von Haushunden in Konfliktsituationen. Z. Psychol. 159, 161-245 - Smith, C. J. V., and B. BRrght-TAyLor (1947): Does a glucostatic mechanism for tood intake control exist in chickens? Poultry Science 53, 1720-1724 - ScotT, A. P., J. F. Ratclife, L. H. Rees, H. P. J. Bennet, P. J. Lowry and C. McMartin (1973): Pituitary peptides. Nature New Biol. 244, 65-67 - Sigma Chemical Co. (1971): The colorimetric determination of glucose in whole blood, plasma or serum. Sigma Techn. Bull. 635 - STEFFEns, A. B. (1969): Rapid absorption of glucose in the intestinal tract of the rat after ingestion of a meal. Physiol. Behav. 4, 829-832 - STERBA, G. (ed.) (1969): Zirkumventrikuläre Organe und Liquor. Fischer, Jena.

Author's address: Juan D. Delius, Psychologisches Institut, Experimentelle Tierpsychologie, Ruhr-Universität Bochum, D-463 Bochum-Quercnburg, Universitätsstr. 150. 